\title{
About term distribution in categorical syllogisms
}

\author{
Dan Constantin Radulescu
}

\begin{abstract}
One uses a set interpretation of the terms appearing in categorical syllogisms, to redefine the term distribution notion such that most of the valid categorical arguments (VCAs), (which contain as a subset all the valid syllogisms (VSs)), "conserve the distribution of terms", i.e., the terms that appear in the logical conclusion (LC) of a VCA and are there distributed, (resp. undistributed), were also distributed, (resp. undistributed), in the pair of categorical premises (PCP) that generated the VCA by entailing its $L C$. The following criterion redefines term distribution: The sets which are distributed, (resp. undistributed), in an universal categorical statement are undistributed, (resp. distributed), in its contradictory particular statement. Thus, by definition, $I(M, P)$ does not distribute $M$ and $P$ since $E(M, P)$ does, but distributes $M^{\prime}$ and $P^{\prime}$ since $E(M, P)$ does not, and $O(M, P)$ does not distribute $M$ and $P^{\prime}$ since $A(M, P)$ does, but distributes $M^{\prime}$ and $P$ since $A(M, P)$ does not.
\end{abstract}

Keywords. Pairs of categorical premises (PCPs) • logical conclusions $(L C s) \cdot v a l i d$ categorical arguments (VCAs) - term distribution • Venn diagram $\bullet$ valid syllogisms (VSs) $\bullet$ categorical statement

\section{Term distribution and its conservation}

The distribution concept and the rules of syllogisms were examined in a detailed and clear way, e.g., in Miller (1938), pp. 68-83, who proposed definitions for a strong and a weak distribution. This paper's definition produces a distribution table "in between" those produced by the two Miller's definitions on p.73.

Instead of the "figures, moods and rules of the syllogism approach", which satisfies "Aristotle's requirement that the middle term $\mathrm{M}$ should not appear in the conclusion, (Striker 2009, p.20: "A syllogism is an argument in which, certain things being posited, something other than 
what was laid down results by necessity because these things are so."), one adopts a set or Venn diagram approach, which deals mainly with the eight 3-set intersections that span a universal set U: $\mathrm{U}=\mathrm{MSP}+\mathrm{MS}$ 'P+MSP'+MS'P'+ M'SP+ M'S'P + $\mathrm{M}^{\prime} \mathrm{SP}^{\prime}+\mathrm{M}^{\prime} \mathrm{S}^{\prime} \mathrm{P}^{\prime}$, where $\mathrm{S}, \mathrm{P}, \mathrm{M}$ are the usual categorical terms (interpreted now as sets) appearing in the wording of the PCPs and of the LCs which the PCPs might entail; the union of disjoints sets is denoted by a + sign; $\mathrm{MSP}:=\mathrm{M} \cap \mathrm{S} \cap \mathrm{P}$, etc.; $\mathrm{S}^{\prime}, \mathrm{P}^{\prime}, \mathrm{M}^{\prime}$ are the categorical terms non-S, non-P, non-M, now interpreted as the complementary sets in U of the S,P, M, respectively. In this approach, the middle term $\mathrm{M}$, and $\mathrm{M}^{\prime}$, are very much a part of each precise LC from which one may finally eliminate $\mathrm{M}$ and $\mathrm{M}$ ' to arrive at a less precise, but usual LC. The "partial term distribution conservation law" in this paper refers to the "usual LCs" from which the middle term was eliminated.

Most textbook definitions of distribution start from the idea that a term is distributed in any of the A,O,E,I categorical statements if that statement refers to each element of the set that "represents" the term. Thus, convincingly, in $\mathrm{A}(\mathrm{S}, \mathrm{P})=$ "All $\mathrm{S}$ are $\mathrm{P}$ ", $\mathrm{S}$ is distributed and $\mathrm{P}$ is not, (because $\mathrm{S} \subseteq \mathrm{P})$, in $\mathrm{E}(\mathrm{S}, \mathrm{P})$ both $\mathrm{S}$ and $\mathrm{P}$ are distributed, (because the whole set $\mathrm{S}$ and the whole set $\mathrm{P}$ do not intersect), in $\mathrm{I}(\mathrm{S}, \mathrm{P})$ neither $\mathrm{S}$ nor $\mathrm{P}$ is distributed, (since $\mathrm{S}$ and $\mathrm{P}$ just have at least one element in common). Less convincing is that in $\mathrm{O}(\mathrm{S}, \mathrm{P}), \mathrm{P}$ is distributed and $\mathrm{S}$ is not; one justifies this choice by arguing that the existence of an $x \in S$ such that $x \notin P$ affirms something about each element of $P$ - namely that is different from $x$. Since the whole $P$ is thus "separated" from $x, P$ is distributed in $\mathrm{O}(\mathrm{S}, \mathrm{P})$. Note that $\mathrm{E}(\mathrm{S}, \mathrm{P})$ means not only $S M=\varnothing$, but also $S \subseteq P^{\prime}$ and $P \subseteq S$ ', and thus to make the distribution concepts for $A(S, P)$ and $\mathrm{E}(\mathrm{S}, \mathrm{P})$ agree, one has to say that $\mathrm{E}(\mathrm{S}, \mathrm{P})$ does not distribute $\mathrm{S}^{\prime}$ and $\mathrm{P}^{\prime}$, and also that $\mathrm{A}(\mathrm{S}, \mathrm{P})$ distributes $\mathrm{S}$ and $\mathrm{P}^{\prime}$, (since $\mathrm{SP}^{\prime}=\varnothing$ ), and does not distribute $\mathrm{P}$ and $\mathrm{S}^{\prime}$ (since $\mathrm{S} \subseteq \mathrm{P}$ and $\mathrm{P}^{\prime} \subseteq \mathrm{S}^{\prime}$ ). Then, to keep the term distribution definition unambiguous, one declares that passing from one categorical statement to its contradictory statement switches around the distribution of the terms involved. Thus, by definition, $\mathrm{I}(\mathrm{S}, \mathrm{P})$ does not distribute $\mathrm{S}$ and $\mathrm{P}$, since $\mathrm{E}(\mathrm{S}, \mathrm{P})$ does, and $\mathrm{I}(\mathrm{S}, \mathrm{P})$ does distribute $\mathrm{S}^{\prime}$ and $\mathrm{P}^{\prime}$, since $\mathrm{E}(\mathrm{S}, \mathrm{P})$ does not. Analogously, $\mathrm{O}(\mathrm{S}, \mathrm{P})$ ), does not distribute $\mathrm{S}$ and $\mathrm{P}^{\prime}$ but distributes $\mathrm{P}$ and $\mathrm{S}^{\prime}$, because $\mathrm{A}(\mathrm{S}, \mathrm{P})$ distributes $\mathrm{S}$ and $\mathrm{P}^{\prime}$, but does not distribute $\mathrm{P}$ and $\mathrm{S}^{\prime}$.

Any PCP is made of one of the six P-premises, E(M,P), $\mathrm{A}(\mathrm{M}, \mathrm{P})=\mathrm{E}\left(\mathrm{M}, \mathrm{P}^{\prime}\right), \mathrm{A}(\mathrm{P}, \mathrm{M})=\mathrm{E}\left(\mathrm{M}^{\prime}, \mathrm{P}\right)$, $\mathrm{O}(\mathrm{M}, \mathrm{P})=\mathrm{E}\left(\mathrm{M}, \mathrm{P}^{\prime}\right), \mathrm{O}(\mathrm{P}, \mathrm{M})=\mathrm{I}\left(\mathrm{M}^{\prime}, \mathrm{P}\right), \mathrm{I}(\mathrm{M}, \mathrm{P})$, and one of the six S-premises, $\mathrm{E}(\mathrm{M}, \mathrm{S}), \mathrm{A}(\mathrm{M}, \mathrm{S})=\mathrm{E}\left(\mathrm{M}, \mathrm{S}^{\prime}\right)$, $\mathrm{A}(\mathrm{S}, \mathrm{M})=\mathrm{E}\left(\mathrm{M}^{\prime}, \mathrm{S}\right), \mathrm{I}(\mathrm{M}, \mathrm{S}), \mathrm{O}(\mathrm{M}, \mathrm{S})=\mathrm{I}\left(\mathrm{M}, \mathrm{S}^{\prime}\right), \mathrm{O}(\mathrm{S}, \mathrm{M})=\mathrm{I}\left(\mathrm{M}^{\prime}, \mathrm{S}\right)$. The $\mathrm{E}$ and A statements are "universal" and the I and O statements are "particular". The 36 PCPs fall into 5 categories, two of them, the PCPs made of two particular premises and the PCPs made of one universal premise and one particular premise acting one on $\mathrm{M}$ and the other on $\mathrm{M}^{\prime}$ - do not entail any LCs. Each of the other PCPs entails at least one LC and thus generates at least a VCA. These rest of the PCPs, (and their generated VCAs), are naturally subdivided into other three classes. As one can see below, the LC of any VCA refers/pinpoints to one and only one of the eight subsets which form the partition of the universal set U. The three classes of VCAs are generated by: (i) Pairs of universal premises both acting on M (or $\mathrm{M}^{\prime}$ ); they may be expressed, e.g., as $\mathrm{E}(\mathrm{M}, \alpha) \mathrm{E}(\mathrm{M}, \beta)$, (where $\alpha \in\left\{\mathrm{P}_{\mathrm{P}} \mathrm{P}^{\prime}\right\}$ and $\beta \in\left\{\mathrm{S}, \mathrm{S}^{\prime}\right\}$ ), and empty three subsets out of the four subsets of $\mathrm{M}$ (in the above partition of $U$ ). The $\mathrm{LC}$ of any such pair is $\mathrm{M}=\alpha^{\prime} \beta^{\prime} \mathrm{M}$, $M \subseteq \alpha^{\prime} \beta^{\prime}$, or $A\left(M, \alpha^{\prime} \beta^{\prime}\right)$. (One may see this by writing $M=M \alpha+M \alpha^{\prime}=M \alpha^{\prime}=M \alpha^{\prime} \beta+M \alpha^{\prime} \beta^{\prime}$.) Thus, the ei supposition $\mathrm{M} \neq \varnothing$, implies $\mathrm{I}\left(\alpha^{\prime}, \beta^{\prime}\right)$. Note that $\alpha^{\prime}, \beta^{\prime}$ are not distributed in the $\mathrm{LC}$, but they were not distributed in the premises, either (since $\alpha$ and $\beta$ were distributed in $E(M, \alpha), E(M, \beta)$ ) One may count $M$ as being distributed in both the premises and the LC. Note the following PCP: A(P,M)A(S,M)=E(M',P) $\mathrm{E}\left(\mathrm{M}^{\prime}, \mathrm{S}\right)$ whose $\mathrm{LC}$ is $\mathrm{M}^{\prime}=\mathrm{M}^{\prime} \mathrm{S}^{\prime} \mathrm{P}^{\prime}$ or $\mathrm{A}\left(\mathrm{M}^{\prime}, \mathrm{S}^{\prime} \mathrm{P}^{\prime}\right)$, and the ei $\mathrm{LC}$ is $\mathrm{I}\left(\mathrm{S}^{\prime}, \mathrm{P}^{\prime}\right)$. Undistributed are $\mathrm{S}^{\prime}, \mathrm{P}^{\prime}$ in both LC and PCP; M' is distributed in both LC and PCP and may be counted as the real middle term instead of $\mathrm{M}$ which is not distributed in either premise. (ii) Pairs made of one particular premise and one universal premise, both acting on $\mathrm{M}$ (or $\left.\mathrm{M}^{\prime}\right)$ ); they may be expressed, e.g., as $\mathrm{I}(\mathrm{M}, \alpha) \mathrm{E}(\mathrm{M}, \beta)$, where $\alpha \in$ $\left\{\mathrm{P}, \mathrm{P}^{\prime}\right\}$ and $\beta \in\left\{\mathrm{S}, \mathrm{S}^{\prime}\right\}$ or vice versa, $\alpha \in\left\{\mathrm{S}, \mathrm{S}^{\prime}\right\}$ and $\beta \in\left\{\mathrm{P}, \mathrm{P}^{\prime}\right\}$. I $(\mathrm{M}, \alpha)$ lays at least one set element in (at least one of) the two subset intersection $\mathrm{M} \alpha$, and $\mathrm{E}(\mathrm{M}, \beta)$ empties $\mathrm{M} \alpha \beta$, thus generating the LC 
$M \alpha \beta^{\prime} \neq \varnothing$, or, with some loss of information, $\mathrm{I}\left(\alpha, \beta^{\prime}\right)=\mathrm{O}(\alpha, \beta)$; note again that $\alpha$ and $\beta^{\prime}$ are not distributed in the conclusion and they were not distributed in the premises, either. $M$ was distributed in one premise but not in the other. (iii) Pairs of universal premises acting on both $M$ and $\mathrm{M}^{\prime}$; they may be expressed as $\mathrm{E}(\mathrm{M}, \alpha) \mathrm{E}\left(\mathrm{M}^{\prime}, \beta\right)$, where $\alpha \in\left\{\mathrm{P}, \mathrm{P}^{\prime}, \mathrm{S}, \mathrm{S}^{\prime}\right\}$ and a different letter is chosen for $\beta$, but only from either $\mathrm{S}$ or $\mathrm{P}$ (no $\mathrm{P}^{\prime}, \mathrm{S}^{\prime}$ choices for $\beta$ since four P-premises act on (or contain) $\mathrm{M}$ and only two act on (or contain) $\mathrm{M}^{\prime}$, and similarly for the S-premises - please see the above list of premises), and empty four subsets - two on M and two on $\mathrm{M}^{\prime}$, with two subsets out of four spanning the intersection $\alpha \beta$ and thus generating $\mathrm{E}(\alpha, \beta)$ as the LC which is "free from the middle terms M and M'". The more precise LCs, to which existential import (ei) can be applied, are easily seen, (again by removing from $\alpha$ and $\beta$ the subsets declared empty by $\mathrm{E}(\mathrm{M}, \alpha)$ and $\left.\mathrm{E}\left(\mathrm{M}^{\prime}, \beta\right)\right)$, to be $\alpha=\alpha \beta^{\prime} \mathrm{M}^{\prime}$ and $\beta=\beta \mathrm{M} \alpha^{\prime} \equiv \alpha^{\prime} \beta \mathrm{M}$. Thus, $\alpha$ and $\beta$ were reduced to only one, possibly not empty, subset; the other three subsets, (out of four), of $\alpha$ and $\beta$ are empty. With some loss of information, the formulas $\alpha=\alpha \beta^{\prime} \mathrm{M}^{\prime}$ and $\beta=\alpha^{\prime} \beta \mathrm{M}$, imply, respectively, $\mathrm{A}\left(\alpha, \beta^{\prime}\right)$ and $\mathrm{A}\left(\beta, \alpha^{\prime}\right)$. Note that $\mathrm{A}\left(\alpha, \beta^{\prime}\right)=\mathrm{A}\left(\beta, \alpha^{\prime}\right)=\mathrm{E}(\alpha, \beta)$ and the terms appearing in this $\mathrm{LC}$ have the same distribution as they had in the premises. The ei supposition $\alpha \neq \varnothing$, implies $I\left(\alpha, \beta^{\prime}\right)$, and the ei supposition $\beta \neq \varnothing$, implies $I\left(\alpha^{\prime}, \beta\right)$. These immediate implications by subalternation do not conserve term distribution, and in this sense one has only a "partial term distribution conservation law".

\section{Conclusions}

With the above unambiguous definition for term distribution, one may check - as in the previous section, that the distribution of the terms appearing in most LCs, (namely all LCs except the existential import (ei) LCs generated by pairs of universal premises acting on both M and $\mathrm{M}^{\prime}$ ), is the same as the distribution of the same terms in the PCP which entailed the LC. The implication by subalternation, (A(S,P) implies I(S,P) and E(S,P) implies $\mathrm{O}(\mathrm{S}, \mathrm{P}))$, does not preserve the term distribution, and that is exactly what is used to generate the ei LCs for type (iii) PCPs. For type (ii) PCPs there do not exist ei LCs, and for type (i) PCPs there exist only ei LCs since, cf. Aristotle's idea of not re-listing the premises, (aka the middle term), in the LC, one discards all the LCs spelling out the middle term, $\mathrm{M}=\alpha^{\prime} \beta^{\prime} \mathrm{M}$, (even if now, using sets, this does not involve any premise relisting), and one retains only their ei versions $I\left(\alpha^{\prime}, \beta^{\prime}\right)$. The above "distribution conservation law" expresses that some parts of the subsets emptied, (resp. endowed with elements), by a PCP remain empty, (resp. endowed with elements), in the LC, too. The distributions of M and $\mathrm{M}^{\prime}$ terms are totally ignored by the above "distribution conservation law" since $\mathrm{M}$ and $\mathrm{M}$ ' are not part of the usual LCs.

\section{References}

Miller, James W., The Structure of Aristotelian Logic (1938), KEGAN PAUL, TRENCH, TRUBNER \& Co. Ltd. Broadway House, Carter Lane, London, E.C., pp. 68-83

Striker, Gisela (Translation, Introduction and Commentary, 2009) Aristotle's Prior Analytics Book I. Oxford University Press (Clarendon Aristotle Series), Oxford, p. 20. 